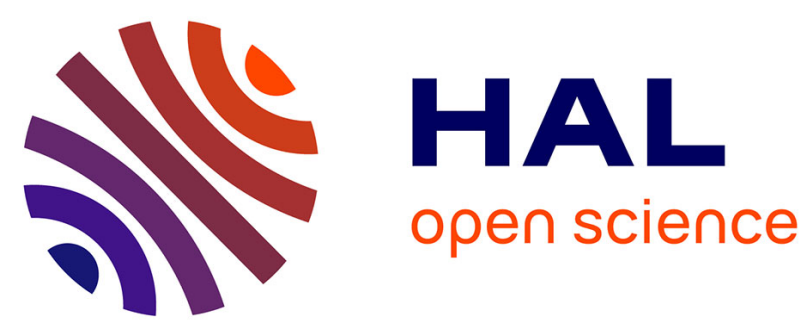

\title{
On-chip multi electrochemical sensor array platform for simultaneous screening of nitric oxide and peroxynitrite
}

Damien Quinton, Aurélie Girard, Loan To Thi Kim, Vincent Raimbault, Laurent Griscom, Florence Razan, Sophie Griveau, Féthi Bedioui

\section{- To cite this version:}

Damien Quinton, Aurélie Girard, Loan To Thi Kim, Vincent Raimbault, Laurent Griscom, et al.. On-chip multi electrochemical sensor array platform for simultaneous screening of nitric oxide and peroxynitrite. Lab on a Chip, 2011, 11 (7), pp.1342-1350. 10.1039/C0LC00585A . hal-00662648

\section{HAL Id: hal-00662648 \\ https://hal.science/hal-00662648}

Submitted on 24 Jan 2012

HAL is a multi-disciplinary open access archive for the deposit and dissemination of scientific research documents, whether they are published or not. The documents may come from teaching and research institutions in France or abroad, or from public or private research centers.
L'archive ouverte pluridisciplinaire HAL, est destinée au dépôt et à la diffusion de documents scientifiques de niveau recherche, publiés ou non, émanant des établissements d'enseignement et de recherche français ou étrangers, des laboratoires publics ou privés. 


\title{
Lab on a Chip
}

\section{On-chip multi-electrochemical sensor array platform for simultaneous screening of nitric oxide and peroxynitrite}

\author{
Damien Quinton, ${ }^{a b}$ Aurélie Girard,${ }^{c}$ Loan To Thi Kim, ${ }^{a b}$ Vincent Raimbault, ${ }^{c}$ Laurent Griscom, ${ }^{c}$ \\ Florence Razan, ${ }^{* c}$ Sophie Griveau ${ }^{a b}$ and Fethi Bedioui ${ }^{* a b}$
}

\author{
Received 11th November 2010, Accepted 13th January 2011 \\ DOI: 10.1039/c0lc00585a
}

\begin{abstract}
In this work we report on the design, microfabrication and analytical performances of a new electrochemical sensor array (ESA) which allows for the first time the simultaneous amperometric detection of nitric oxide (NO) and peroxynitrite $\left(\mathrm{ONOO}^{-}\right)$, two biologically relevant molecules. The on-chip device includes individually addressable sets of gold ultramicroelectrodes (UMEs) of $50 \mu \mathrm{m}$ diameter, $\mathrm{Ag} / \mathrm{AgCl}$ reference electrode and gold counter electrode. The electrodes are separated into two groups; each has one reference electrode, one counter electrode and 110 UMEs specifically tailored to detect a specific analyte. The ESA is incorporated on a custom interface with a cell culture well and spring contact pins that can be easily interconnected to an external multichannel potentiostat. Each UME of the network dedicated to the detection of NO is electrochemically modified by electrodepositing thin layers of poly(eugenol) and poly(phenol). The detection of NO is performed amperometrically at $0.8 \mathrm{~V} v$. $\mathrm{Ag} / \mathrm{AgCl}$ in phosphate buffer solution ( $\mathrm{PBS}, \mathrm{pH}=7.4$ ) and other buffers adapted to biological cell culture, using a NO-donor. The network of UMEs dedicated to the detection of $\mathrm{ONOO}^{-}$is used without further chemical modification of the surface and the uncoated gold electrodes operate at $-0.1 \mathrm{~V} v s$. $\mathrm{Ag} / \mathrm{AgCl}$ to detect the reduction of $\mathrm{ONOOH}$ in PBS. The selectivity issue of both sensors against major biologically relevant interfering analytes is examined. Simultaneous detection of $\mathrm{NO}$ and $\mathrm{ONOO}^{-}$in PBS is also achieved.
\end{abstract}

\section{Introduction}

The simultaneous detection of chemical substances released by living systems and biological samples is of the utmost importance for the elucidation of signal transduction pathways in vivo and also for drug testing by cell-based assays. ${ }^{1}$ The development of sensors that display high sensitivity and selectivity towards targeted molecules, and at the same time are insensitive to interfering chemicals present in complex biological media, is the major hurdle that has to be crossed in order to achieve the simultaneous detection. In spite of their inherent difficulties, electrochemical methods are recognised as being the only labelfree analytical tools able to determine the local flux of biologically active compounds without disturbing their metabolism and the associated regulatory pathways. ${ }^{2-4}$ Electrochemical Sensor Arrays (ESAs) provide an easy access to the simultaneous

${ }^{a}$ Unité de Pharmacologie Chimique et Génétique et Imagerie, CNRS 8151, École Nationale Supérieure de Chimie de Paris, Chimie ParisTech, Université Paris Descartes, Paris, France. E-mail: fethi-bedioui@, chimie-paristech.fr

${ }^{b}$ INSERM, Unité de Pharmacologie Chimique et Génétique et Imagerie (No. 1022), Paris, France

'SATIE, CNRS UMR 8029, Ecole Normale Supérieure de CachanBretagne, Campus de Ker Lann, Bruz, France. E-mail: florence.razan@, bretagne.ens-cachan.fr detection of multiple species, when each individual electrode of the array is specifically tailored to sensitively detect a particular analyte.

In particular, ESAs are well adapted to the study of reactive oxygen and nitrogen species in cellular signal transduction. ${ }^{5-7}$ Among those species, the balance between nitric oxide (NO), superoxide $\left(\mathrm{O}_{2}{ }^{-}\right)$and their reaction product peroxynitrite $\left(\mathrm{ONOO}^{-}\right)$is known to control many essential cell functions including activation, proliferation and apoptosis. This reaction between $\mathrm{NO}$ and $\mathrm{O}_{2}{ }^{-}$is rapid and diffusion-controlled and the product formed, $\mathrm{ONOO}^{-}$, is a very powerful oxidant and cytotoxic agent. Indeed, $\mathrm{ONOO}^{-}$undergoes homolytic or heterolytic cleavage that triggers a cascade of highly reactive molecules including $\mathrm{OH}^{\cdot}$ and $\mathrm{NO}_{2}{ }^{\cdot}$ radicals. ${ }^{8}$ These molecules and their progenitors are the major compounds of oxidative and nitroxidative stress ${ }^{9,10}$ and they are involved in the development of various (cardio)vascular and neurodegenerative pathologies and diseases. For example, in the case of traumatic injury, the deficiency of bioavailable $\mathrm{NO}$ and overproduction of $\mathrm{ONOO}^{-}$ should be closely monitored. ${ }^{11}$ Among all the involved species, and due to their very short lifetimes, only $\mathrm{NO}$ and $\mathrm{ONOO}^{-}$can be monitored simultaneously. The demonstration that $\mathrm{NO} /$ $\mathrm{ONOO}^{-}$balance can be used as a risk marker is tightly linked to the accessibility of an accurate analytical concept. 
Our interest in designing electrochemical sensing devices for biologically relevant species such as $\mathrm{NO}, \mathrm{O}_{2}{ }^{-}$and thiols ${ }^{12-15}$ led us to explore the possibility of tailoring ESAs platforms, in a design that is adapted to cell culture studies, dedicated to the simultaneous detection of $\mathrm{NO}$ and $\mathrm{ONOO}^{-}$. The key step in the development of the desired simultaneous detection is the ability to independently modify each electrode, or group of electrodes, with the appropriate sensing chemistry and to address them with different electrical potentials. Proof of concept and feasibility of different sensing chemistries for the individual detection of NO, $\mathrm{O}_{2}{ }^{-}$and $\mathrm{ONOO}^{-}$was previously demonstrated. ${ }^{15}$ Additionally, the development of platforms integrating embedded electrodes for the detection of NO and other associated compounds on which cells can grow were suggested and developed by several groups. ${ }^{16-26}$ However, only very few examples devoted to the simultaneous detection of 2 or 3 different analytes were reported. ${ }^{17,18}$

In this work we present the design, microfabrication and analytical performances of a new fully integrated ESA for the simultaneous amperometric detection of $\mathrm{NO}$ and $\mathrm{ONOO}^{-}$. The integrated design allows the ESA to be implemented in a cellculture well. The on-chip device includes multiple sets of individually addressable ultramicroelectrodes (UMEs) grouped around two networks where each one is tailored to detect a specific analyte. This method should allow real-time monitoring of the levels and ratios of important but unstable NO and $\mathrm{ONOO}^{-}$biomolecules, and could serve as an important diagnostic tool in biomedical research as well as in primary care situations. The desired characteristics of such platforms should combine a high degree of biocompatibility that allows growing the biological cells directly onto the arrayed electrodes and then minimise the distance between the source of production of $\mathrm{NO} /$ $\mathrm{ONOO}^{-}$and the surface of the sensors with a high density of UMEs to allow amplifying the measured average amperometric signal. Additionally the application of electrochemical arrays to glass substrates can allow the simultaneous observation of cell cultures with continuous monitoring of $\mathrm{NO}$ and $\mathrm{ONOO}^{-}$ concentrations.

\section{Experimental}

\section{Chemicals}

NO donor compound, DEA-NONOate (diethylammonium $(Z)$ 1-( $N, N$-diethylamino)diazen-1-ium-1,2-diolate) was from Cayman Chemical (USA) and kept at $-20^{\circ} \mathrm{C}$. Silver $(99,9 \%)$ wires were from Goodfellow (UK). All other chemicals were reagent grade and were used without further purification. All aqueous solutions were made using ultrapure water with a resistivity of $18.2 \mathrm{M} \Omega \mathrm{cm}$. All experiments were achieved at room temperature $\left(25 \pm 3{ }^{\circ} \mathrm{C}\right)$ in phosphate buffer solution (PBS) $(0.1$ $\mathrm{M} ; \mathrm{pH}=7.4)$. PBS was prepared by mixing $78.2 \mathrm{~mL}$ of $\mathrm{NaOH}$ $(0.1 \mathrm{M})$ with $100 \mathrm{~mL}$ of $\mathrm{NaH}_{2} \mathrm{PO}_{4}(0.1 \mathrm{M})$.

The NO donor stock solutions were prepared by dissolving DEA-NONOate in $\mathrm{NaOH}(0.01 \mathrm{M})$ solution $(10 \mathrm{mM}$ DEANONOate). The obtained solutions were aliquoted and kept at $-20{ }^{\circ} \mathrm{C}$ in the dark for two months maximum. Alkaline stock solutions were thawed immediately before use and release of $\mathrm{NO}$ was initiated by adding aliquots to aerobic PBS $(\mathrm{pH} 7.4)$ at room temperature.
Peroxynitrite was synthesised as previously described. ${ }^{27}$ Briefly, a $250 \mathrm{~mL}$ beaker containing $50 \mathrm{~mL}$ hydrogen peroxide $(50 \mathrm{mM})$ and sodium nitrite $(50 \mathrm{mM})$ is kept on ice with vigorous magnetic stirring. $25 \mathrm{~mL}$ of hydrochloric acid $(0.1 \mathrm{M})$ at room temperature are rapidly added, followed $1 \mathrm{~s}$ later by $25 \mathrm{~mL}$ of ice cold sodium hydroxide $(1.5 \mathrm{M})$ to quench the reaction. Excess hydrogen peroxide was removed by passing the solution over homemade manganese dioxide flakes. ${ }^{28}$ The obtained alkaline stock solution was aliquoted, kept in the dark at $-20^{\circ} \mathrm{C}$ and used within one week. Peroxynitrite concentration of the stock solution was determined prior to experiments by reading the absorbance at $302 \mathrm{~nm}\left(\varepsilon=1705 \mathrm{~L} \mathrm{~mol}^{-1} \mathrm{~cm}^{-1}{ }^{29}\right)$. It is important to note that unreacted nitrite might be still present in the final solution, and therefore this should be taken into account in every experiment using peroxynitrite synthesised from this method.

One hundred $\mu \mathrm{M}$ dopamine (DA), $100 \mu \mathrm{M}$ hydrogen peroxide $\left(\mathrm{H}_{2} \mathrm{O}_{2}\right), 200 \mu \mathrm{M}$ sodium nitrite, $250 \mu \mathrm{M}$ glutamate (Glu) and 500 $\mu \mathrm{M}$ ascorbic acid (AA) were used to evaluate the selectivity of the ESAs against electrochemical interfering analytes.

\section{Design and microfabrication of the ESAs}

Design. The ESAs were grouped into two networks in view to simultaneously detect $\mathrm{NO}$ and $\mathrm{ONOO}^{-}$. In this two-in-one integrated electrochemical system, all the electrodes were arranged in matching pairs: two sets of multiples working UMEs, two counter-electrodes and two reference electrodes. Moreover, the pattern was included in a $15 \mathrm{~mm}$ diameter circle to simulate a cell culture well. The structure of the ESA is shown in Fig. 1. The counter electrodes were designed in two parts as 2 semicircles surrounding the working UMEs with a $14 \mathrm{~mm}$ diameter. The width of these electrodes is $500 \mu \mathrm{m}$ giving a $9.9 \mathrm{~mm}^{2}$ surface area. The reference electrodes were arranged in the centre and represent two $5 \times 0.25 \mathrm{~mm}$ bars with a surface area of $1.25 \mathrm{~mm}^{2}$ each. The working UMEs have a disc shape of 50 microns in diameter with a hexagonal spacing arrangement of $500 \mu \mathrm{m}$. Indeed, to insure a radial diffusion of the electroactive species and an additive current measurement, the geometry of the ESA is chosen so that the UMEs are spaced equidistantly at a gap (that is at least ten times the electrode diameter) to avoid overlapping of the diffusion layers during the electrochemical experiments. ${ }^{30,31}$ Seven sets of seven short-circuited UMEs and one set of 61 short-circuited UMEs composed of each network of the ESA. Thus each network comprises 110 UMEs, one band shaped reference electrode and one semi-circle shaped counter electrode (Fig. 1b).

Microfabrication. Standard microfabrication methods and equipment were used to satisfy the strict purity requirements for sensitive electrochemical detection. The cleanroom microfabrication process can be described in three phases. The first phase involves patterning gold leads for the ESAs on $1 \mathrm{~mm}$ thick glass substrates. The leads, in the second phase, are then uniformly insulated with a one micron Parylene-C coating, which is patterned and etched by a reactive ion etching (RIE) process to define the microelectrode array. In the final phase, the silver is electro-deposited and transformed to $\mathrm{AgCl}$ to integrate the reference electrodes. 
(a)
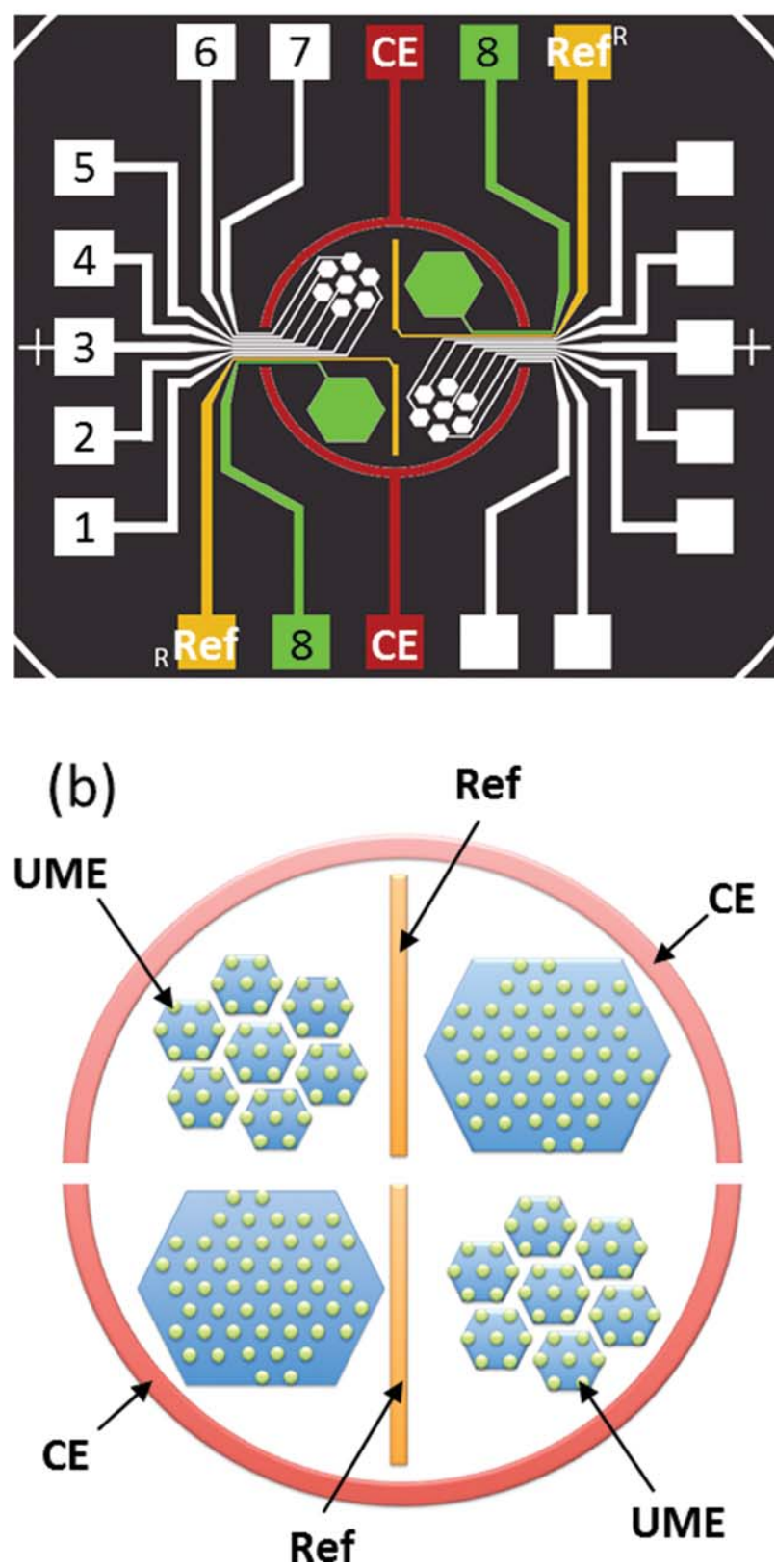

Fig. 1 (a) Layout and design of the ESA is contained on a $50 \mathrm{~mm}$ circular wafer. The electrical connections are permitted through 20 pads arranged around the periphery. (b) The arrayed UMEs are contained within the confines of the counter electrodes (CE) which are two half circles with a $7.5 \mathrm{~mm}$ radius. There are two reference electrodes which are centred vertical bars (Ref). The working UMEs are defined by the etching of the Parylene insulating layer on the gold electrode areas (hexagonal patterned pads). They can be addressed in sets of 7 electrodes (pads 1-7) or as a larger one (pad 8).

All metals used for the photolithography process were $99.99 \%$ quality, supplied by Neyco, SA. Thin film deposition machine (Plassys ME300) was used to deposit Ti and Au layers by thermal evaporation. The Parylene was deposited by chemical vapour deposition using a SCS Labcoater. Parylene was etched using a VAS (Vacuum Air Systems) RIE machine. The Parylene etching process parameters were 60 standard cubic centimetre per minute $\mathrm{O}_{2}$ at $0.1 \mathrm{mbar}$ and $100 \mathrm{~W}$ RF power for 20 minutes.

To begin the process and ensure high purity, the substrates are cleaned using $1 \%$ Hellmanex in demineralised water for two hours in an ultrasound bath at $40{ }^{\circ} \mathrm{C}$ and then rinsed abundantly in demineralised water. Titanium and gold (30 nm and $200 \mathrm{~nm}$ respectively) were sequentially deposited by thermal evaporation under high vacuum $\left(P<1 \times 10^{-6} \mathrm{mbar}\right)$ on the cleaned substrates. The leads and electrodes were then defined photolithographically using Shipley S1818 positive tone photoresist and chemically etched using a VSLI Titanium Etchant and Gold Etchant. These patterns were, in turn, electrically insulated using a $1 \mu \mathrm{m}$ Parylene-C passivation coating. ${ }^{32}$ In early prototypes, the passivation of the gold electrodes was initially fabricated using SU-8 photosensitive resin, as it is often used for commercial microelectrode arrays. However the SU-8 was not suitable in the present case, as it provoked the pollution of the electrode surfaces and it was degraded by the electrochemical deposition of phenol used as a selective barrier. Parylene was retained for its chemical resistance and inertness, and the plasma etching process ensured clean electrode surfaces after removal. The uniform coating was subsequently patterned using S1818 photoresist to define the microelectrode array including the working UMEs, counter and reference electrodes, as well as the pads for connection to the external potentiostats.

To create the integrated $\mathrm{Ag} / \mathrm{AgCl}$ reference electrode, $\mathrm{Ag}$ was electro-deposited directly on the reference electrode as follows: the substrate was submerged in a $1 \mathrm{~mL}$ solution of citric acid $(15 \mathrm{mM})+$ silver nitrate $(0.2 \mathrm{M})+$ nitric acid $(0.1 \mathrm{M})^{33}$ and $\mathrm{Ag}$ was electro-deposited galvanostatically by applying a constant current of $-250 \mu \mathrm{A}$ to the reference electrode for fifteen minutes. These parameters led to the formation of $2 \mu \mathrm{m}$ thick silver deposits, which was then carefully rinsed and dried, before being electrochemically oxidised in saturated $\mathrm{KCl}$ solution by applying $+1.5 \mathrm{~V}$ to form $\mathrm{AgCl}$. This method gave stable and durable integrated reference electrode in contrast to other methods such as thermal evaporation of $\mathrm{Ag}$.

\section{Electrochemical techniques and surface characterisation}

For all the electrochemical experiments, the ESA was inserted in a two part cell (Fig. 2). The first piece consists of an aluminium

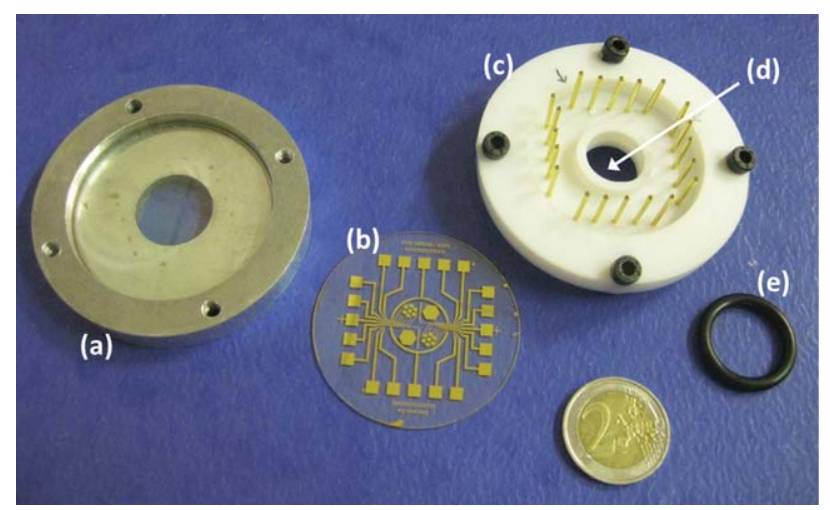

Fig. 2 Photography of the two part cell: aluminium base plate (a) supporting the ESA (b) and Teflon upper part (c) with pins that assure electrical contacts and contain the well (d) and o-ring sealing (e). 
base plate (Fig. 2a) supporting the ESA platform (Fig. 2b) and the second upper part made of Teflon contains 20 sprung gold plated pins (Fig. 2c), which assure electrical contacts and a $15 \mathrm{~mm}$ diameter reservoir for the reception of liquids above the electrodes (Fig. 2d). The well was sealed using an o-ring (Fig. 2e) that was clamped between the top and bottom plates.

All the electrochemical experiments were performed at room temperature $\left(25 \pm 3{ }^{\circ} \mathrm{C}\right)$ in aerated conditions. Either $\mathrm{Ag}$ wire electrochemically coated by $\mathrm{AgCl}$ placed in the electrochemical cell or the embedded $\mathrm{Ag} / \mathrm{AgCl}$ band electrode fabricated within the ESA was used as reference electrode. Identical results were obtained when using either the external or the internal pseudoreference electrode.

Cyclic voltammetry and chronoamperometry experiments were carried out using a Princeton Applied Research potentiostat (model 263A) or Picostat (eDAQ) or QuadStat (eDAQ). Chronoamperometric measurements of simultaneous detection of $\mathrm{NO}$ and $\mathrm{ONOO}^{-}$were achieved by using common reference and counter electrode for both sensors.

Scanning electrochemical measurements (SECM) were conducted on the planar UMEs to evaluate their electrochemical reactivity. SECM experiments were carried out using a Princeton Applied Research equipment (UNISCAN Model 370) and homemade $25 \mu \mathrm{m}$ Pt microelectrode as the tip. SECM images were obtained by maintaining the tip at a constant $z$ position and scanning in the $x-y$ plane over the desired area (constant-height mode of SECM) and monitoring changes in the steady-state current of potassium hexacyanoferrate(II) oxidation at $0.5 \mathrm{~V}$ vs. external $\mathrm{Ag} / \mathrm{AgCl}$ as the tip travels.

AFM experiments were performed with a DI-Caliber AFM system from VEECO Instruments with a claimed resolution of $0.1 \mathrm{~nm}$. Alpha Step IQ surface profiler (KLA Tencor) was used to evaluate the profile of the surface of the constructed ESAs.

\section{Electrochemical measurement of NO}

UMEs dedicated to the detection of NO were coated with poly(eugenol) and poly(phenol) layers to ensure adequate selectivity. First, the electrodes were treated in an aqueous solution of eugenol $(10 \mathrm{mM})+$ sodium hydroxide $(0.1 \mathrm{M})$ by applying a potential of $150 \mathrm{mV}$ vs. $\mathrm{Ag} / \mathrm{AgCl}$ for $15 \mathrm{~min}$, allowing the electrodeposition of a poly(eugenol) layer. Poly(phenol) layer was then deposited on top of the poly(eugenol) layer by cyclic voltammetry, by scanning the potential of the UMEs between 0 and $0.7 \mathrm{~V} v s$. $\mathrm{Ag} / \mathrm{AgCl}$ at a rate of $10 \mathrm{mV} \mathrm{s}^{-1}$ for 10 cycles in PBS $(0.1 \mathrm{M} ; \mathrm{pH}=7.4)+\operatorname{phenol}(0.5 \mathrm{M})$.

For NO measurements, a potential of $0.8 \mathrm{~V}$ vs. $\mathrm{Ag} / \mathrm{AgCl}$ was applied to the UMEs, and NO release was induced by adding aliquots of alkaline stock solution of $\mathrm{NO}$ donor compound (DEA-NONOate) to aerobic PBS ( $\mathrm{pH}=7.4$ ) followed by rapid mixing using a micropipette. NO-release profiles from decomposition of DEA-NONOate $(10 \mu \mathrm{M})$ at chemically modified UMEs were measured in various buffer solutions: PBS, Dulbecco's Modified Eagle's Medium (DMEM), minimum essential eagle medium (MEM) and Roswell Park Memorial Institute medium (RPMI).

Additional coating of the ESAs by fibronectin (Fn) was also

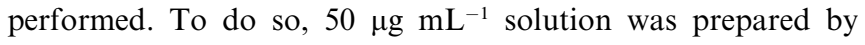
dissolving $\mathrm{Fn}$ from bovine plasma in $\operatorname{PBS}(0.1 \mathrm{M} ; \mathrm{pH}=7.4)$.
The Fn coating was formed by drying at air and at room temperature $1 \mathrm{~mL}$ of fresh solution of Fn on the entire surface of ESAs platforms up to $24 \mathrm{~h}$, followed by rinsing with PBS.

\section{Electrochemical measurement of $\mathrm{ONOO}^{-}$}

UMEs dedicated to the detection of $\mathrm{ONOO}^{-}$were uncoated bare gold electrodes poised at a potential of $-0.1 \mathrm{~V}$ vs. $\mathrm{Ag} / \mathrm{AgCl}$. Aliquots of $\mathrm{ONOO}^{-}$alkaline stock solution were added to aerobic PBS $(\mathrm{pH}=7.4)$ close to the UMEs. Unlike for NO detection, the solution was not mixed with a micropipette because this would hide the $\mathrm{ONOO}^{-}$-related amperometric signal.

\section{Results}

\section{Characterisation of the arrayed UMEs}

The geometrical features and dimensions of the fabricated ESAs were characterised using optical photography, AFM and surface profiler; while the electrochemical behaviour of the UMEs was studied using SECM and $\mathrm{K}_{4} \mathrm{Fe}(\mathrm{CN})_{6}$ redox probe. Fig. 3a shows an optical photography of a group of 7 UMEs. The geometrical area of the electrodes is defined by the holes left in the Parylene insulating layer after the etching process. Profilometry measurements (not shown) indicate that the thickness of the Parylene layer is $1.2 \mu \mathrm{m}$; it corresponds to the recession height of the electrodes. Fig. 3b shows an AFM image of a single UME. This technique confirms that the electrode has a diameter of $50 \mu \mathrm{m}$, and indicates that the gold surface has a roughness value (rms) of $7 \mathrm{~nm}$ while the Parylene layer shows a rms of $5 \mathrm{~nm}$. On the micrometre scale, both Parylene and gold surfaces appear essentially flat.

The UMEs composing the ESA were further characterised with SECM. This technique is based on faradaic current changes at a tip that is moved across the surface of a sample (the ESA in this case). The obtained images depend on the sample topography and surface conductivity; they reveal the exact electrochemically accessible area rather than only topographical features. ${ }^{34}$ Fig. 3c shows the SECM image of 7 UMEs. This image allows visualising the shape of the electrochemically active UMEs by showing the expected differences in amperometric current measured above the insulating Parylene area and the conducting UMEs.

Finally, cyclic voltammetry of the reversible redox couple $\mathrm{Fe}(\mathrm{CN})_{6}{ }^{3-14-}$ was used to characterise the UME-like electrochemical behaviour of the ESA. The objective is two-fold. Firstly, this mediator is very sensitive to the state of the electrode surface and is a good tool to check the absence of adsorbed contaminant species that can hinder the expected electrochemical behaviour for UMEs. Secondly, it is necessary to check that the design of the arrayed UMEs does not affect their individual independent radial diffusion. Indeed, the rationale behind the construction of the ESAs is that they behave as UMEs in terms of spherical diffusion leading to steady state currents and enhanced signal/noise ratio, but with currents intensities similar to macroelectrodes. For arrays of disc-shaped UMEs it has been proposed that the centre-to-centre distance must be 10 times the diameter of an individual $\mathrm{UME}^{31,35}$ to avoid, when they are placed too closely to each other, the overlapping of their 
(a)

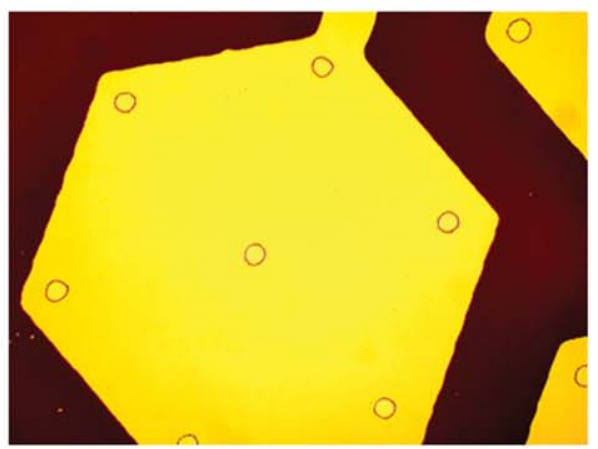

(b)

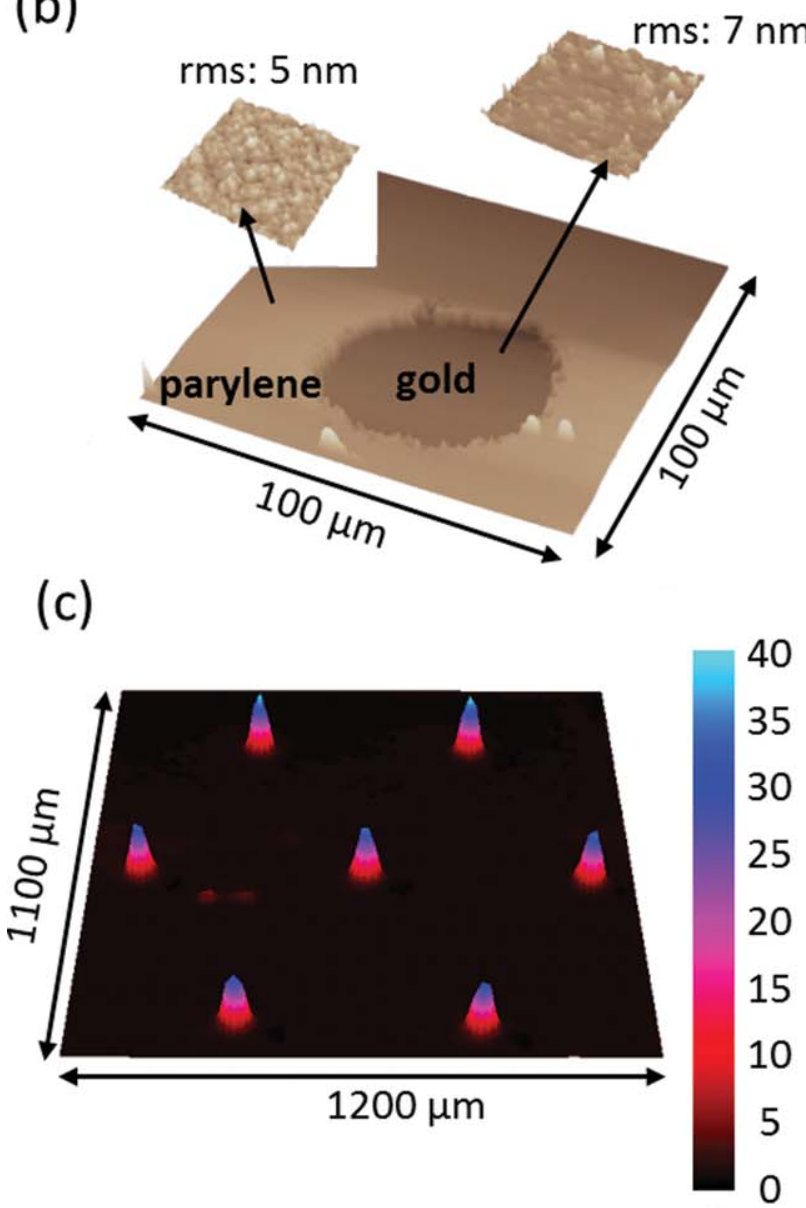

Tip current scale / nA

Fig. 3 (a) Photography of a group of 7 electrodes that are defined by the etching of the Parylene passivation layer. In this case the etched area is $50 \mu \mathrm{m}$ in diameter with $500 \mu \mathrm{m}$ inter-electrode spacing. (b) AFM image of one gold UME surrounded by Parylene within the ESA and (c) SECM image of a group of 7 UMES.

diffusion layers which leads to the loss of steady state currents. Although this criterion was used for the design of the studied ESAs, it is very important to check the diffusional independence of any newly designed array of UMEs. ${ }^{36}$ Fig. 4 a shows the cyclic voltammograms of arrays of 7, 49 and $110 \mathrm{UMEs}$ in $\mathrm{K}_{4} \mathrm{Fe}(\mathrm{CN})_{6}$ (a)

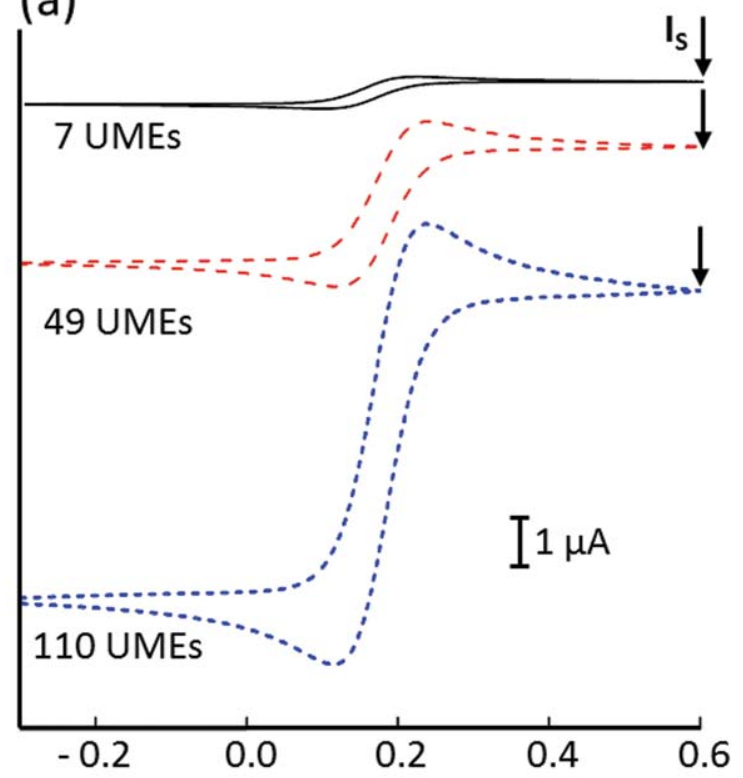

(b)

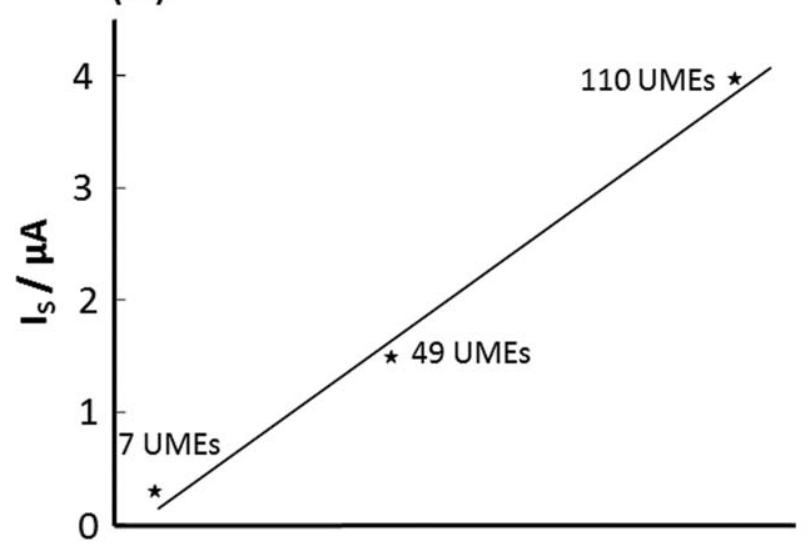

Number of UMEs

Fig. 4 (a) Cyclic voltammograms (scan rate: $50 \mathrm{mV} \mathrm{s}^{-1}$ ) at 7, 49 and 110 UMEs in aqueous solution containing $\mathrm{K}_{4}\left[\mathrm{Fe}(\mathrm{CN})_{6}\right](5 \mathrm{mM})$; (b) linear variation of steady current $\left(I_{\mathrm{s}}\right)$ vs. number of short-circuited UMEs.

solution. Fig. 4b illustrates the linear relationship between the current intensity recorded at $0.6 \mathrm{~V}$ and the number of UMEs in the array, as expected for UMEs with non-overlapping diffusion layers.

The different characterisations show that the ESAs fabricated in this work are fully functional, and that their individual UMEs are electrochemically active and do not suffer from diffusional cross-talk at the time-scale of the experiments.

\section{Electrochemical sensing of NO}

To achieve selective electrochemical oxidation of NO without interference from other products, surface modification of the electrode is necessary. ${ }^{\mathbf{1 2 , 1 5}} \mathrm{NO}$ is electrochemically oxidizable at conventional electrode materials at high potential values, in the range of $0.7-1 \mathrm{~V}$ vs. $\mathrm{Ag} / \mathrm{AgCl}$ in aqueous solutions at 
$\mathrm{pH}$ 7.4..$^{2,15,37,38}$ Such high operating potential values systematically lead to concurrent oxidation of many species present in biological medium, such as ascorbic acid, dopamine, nitrite, hydrogen peroxide etc. thus creating interfering electrochemical signals. This list of potential interfering molecules is not exhaustive but it represents the most commonly encountered electroactive species when it comes to detect $\mathrm{NO}$ in biological systems. ${ }^{15}$ To solve this point, the UMEs of the ESA were coated by electropolymerized eugenol and phenol films. Indeed, previous experiments showed that the combination of poly(eugenol) with poly(phenol) - among several other layered materials-allows obtaining the desired selectivity towards NO. ${ }^{39}$ In the present case, the electrochemical modification of the surface of UMEs was performed as indicated in the Experimental section.

The electrochemical determination of NO-release profile from DEA-NONOate was studied with the modified UMEs by amperometry at $+0.8 \mathrm{~V}$ vs. $\mathrm{Ag} / \mathrm{AgCl}$ in $\mathrm{PBS}(\mathrm{pH}=7.4)$. The reference electrode was either an external wire or the internal embedded band shaped electrode; both configurations gave similar results. After stabilisation of the background current for ca. 15 minutes, an aliquot of alkaline DEA-NONOate stock solution was rapidly mixed and the production of $\mathrm{NO}$ was followed by measuring the evolution of the oxidation current with time. Fig. 5a shows the obtained amperograms. As soon as DEANONOate is injected and mixed, a fast increase of the current is observed, due to the oxidation of the spontaneously released NO, up to a maximum. Then, a relatively slow decrease of the current is observed as soon as the oxidation of NO by molecular oxygen present in the aerated electrolytic solution dominates the overall reaction. The shape of the obtained chronoamperogram is similar to that previously obtained with single disc or needle type ultramicroelectrode ${ }^{40}$ and is indicative of the expected detection of NO released from the donor. Inset of Fig. 5a clearly shows that when the different sets of UMEs are short-circuited (to connect 7, 49 and 110 UMEs) the expected additive currents are obtained. Fig. $5 \mathrm{~b}$ shows the calibration curve of the sensor (110 UMEs) within a dynamic range of $0.1-7 \mu \mathrm{M}$, which gives a sensitivity of $0.56 \mathrm{nA} \mu \mathrm{M}^{-1}$. The theoretical limit of detection of this sensor, calculated for a signal/noise ratio of 3, is $27 \mathrm{nM}$. These analytical characteristics are in the same range as the various previously reported ones ${ }^{12,15}$ despite the differences in shape, configurations and dimensions of the sensors.

Fig. 6 shows the sensitivities of the modified UMEs toward nitrite, hydrogen peroxide, ascorbic acid and dopamine compared to their sensitivity to NO. The data indicate that the modified UMEs discriminate efficiently between $\mathrm{NO}$ and the interfering species. The fact that the layers of poly(eugenol) and poly(phenol) block the interfering species while allowing NO to reach the electrode surface is probably due to steric effect or hydrophilic/hydrophobic interactions. ${ }^{12}$ It is noteworthy that the layers effectively reject negatively charged (nitrite and ascorbic acid), positively charged (dopamine) and neutral (hydrogen peroxide) interferents. Note that the concentrations of the interfering analytes and $\mathrm{NO}$ used here to test the performances of the electrodes were restricted to those expected in biological models. ${ }^{15,25,38}$

It should also be noted that not only the presence of oxidizable electroactive molecules can trouble the electrochemical
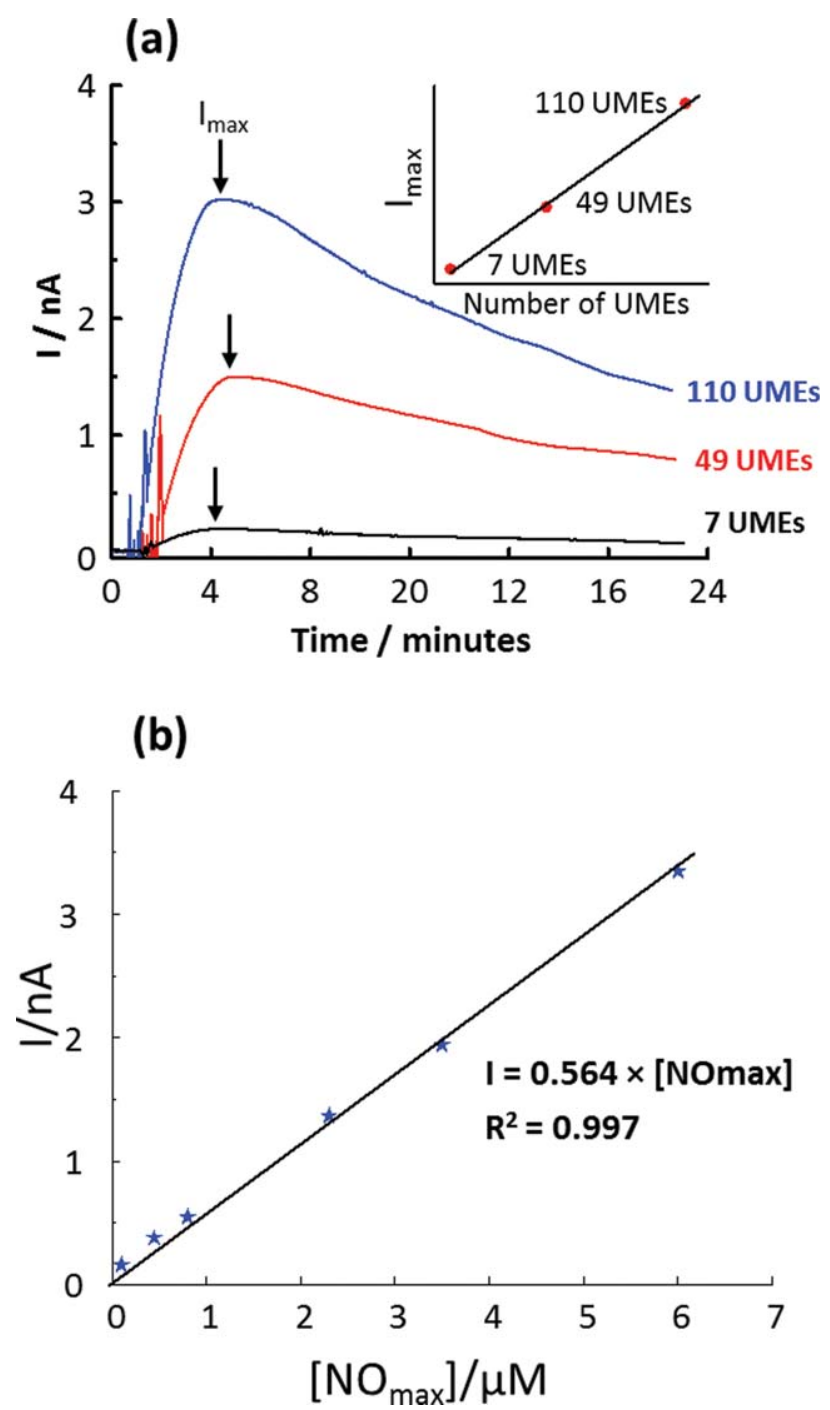

Fig. 5 (a) NO-release profiles in aerobic phosphate buffer solution (pH 7.4) at $25^{\circ} \mathrm{C}$ followed by amperometry at $+0.8 \mathrm{~V} v s . \mathrm{Ag} / \mathrm{AgCl}$ at 7,49 and 110 UMEs coated by Poly(eugenol)/poly(phenol) from decomposition of DEA-NONOate $(10 \mu \mathrm{M})$. Inset: maximal current of NO released vs. number of short-circuited UMEs. (b) Calibration curve of 110 short circuited UMEs.

measurements of NO in biological systems. Indeed, components of the biological buffers themselves can chemically react with $\mathrm{NO}$ and their presence can significantly lower its concentration by providing additional decomposition pathways. So, they do not interfere with the measurement itself, but for a similar concentration of NO donor, the available amount of $\mathrm{NO}$ and its actual concentration may vary depending on the milieu. Studies examining the behaviour of electrochemical sensors in various buffers apart from PBS are rare, notwithstanding the fact their chemical composition may affect the sensitivity of the measurements. Table 1 compares the currents recorded in different media usually used for cell culture, for the same concentration of NO donor. In all cases, the currents are lower than in PBS, and the decrease is more pronounced when indicators (needed for the control of the $\mathrm{pH}$ value during the culture of cells) are present. This is probably due to quenching of NO by various chemical 


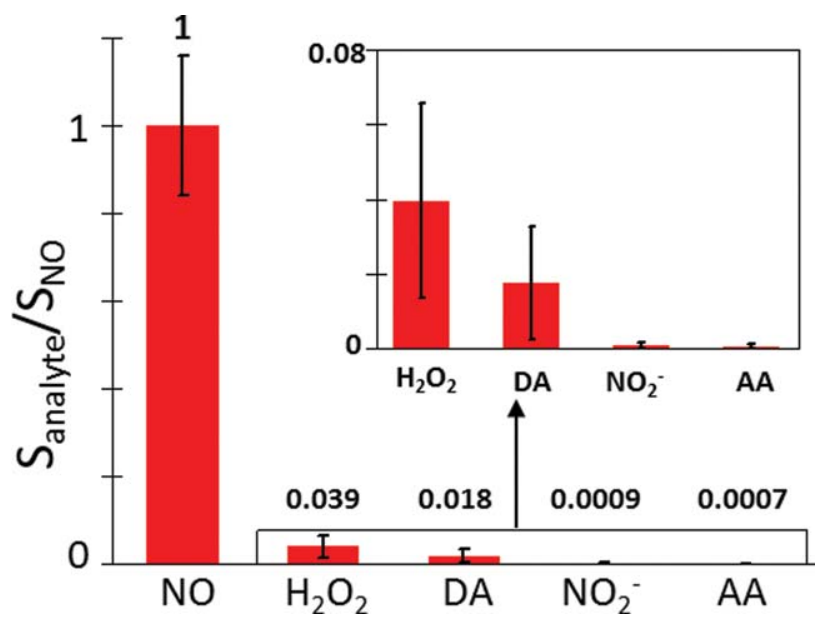

Fig. 6 Comparative representation of the ratio of the sensitivity $(S)$ of sets of gold UMEs coated with poly(eugenol)/poly(phenol) films for $\mathrm{NO}_{2}{ }^{-}(200 \mu \mathrm{M})$, AA $(500 \mu \mathrm{M})$, DA $(100 \mu \mathrm{M})$ and $\mathrm{H}_{2} \mathrm{O}_{2}(100 \mu \mathrm{M})$ over that towards $3.5 \mu \mathrm{mol} \mathrm{L}^{-1} \mathrm{NO}$ in PBS (measured at $0.8 \mathrm{~V} v$ s. $\mathrm{Ag} / \mathrm{AgCl}$ ).

Table 1 Comparison of the sensitivity $(S)$ of sets of NO-sensor array towards NO produced in PBS and in various buffers from decomposition of $10 \mu \mathrm{M}$ of DEA-NONOate (evaluated from amperometric measurements at 0.8 vs. $\mathrm{Ag} / \mathrm{AgCl}$ )

\begin{tabular}{ll}
\hline Buffer & $S_{\text {in a given buffer }} / S_{\text {in PBS }}$ \\
\hline PBS & 1 \\
RPMI without indicator & 0.75 \\
RPMI with indicator & 0.32 \\
DMEM without indicator & 0.38 \\
DMEM with indicator & 0.24 \\
MEM without indicator & 0.3 \\
MEM with indicator & 0.16 \\
\hline
\end{tabular}

components of the buffers. The decrease is less than one order in magnitude, which allows the detection of NO in those media with acceptable sensitivity. These results also show that among the tested media it would be better to use RPMI free of indicators.

Finally, biofouling of the electrode surface by macromolecules is another issue that can lead to the decrease of the sensitivity of the sensors. We found that after the adsorption of fibronectin, an adhesion protein of the extracellular matrix, the sensors retained $80 \%$ of their sensitivity to NO.

\section{Electrochemical sensing of peroxynitrite}

Determination of $\mathrm{ONOO}^{-}$through its electrochemical reduction or oxidation was previously reported using chemically modified electrodes with manganese porphyrin or phthalocyanine at $-0.3 \mathrm{~V}$ vs. $\mathrm{Ag} / \mathrm{AgCl}^{41-43}$ and platinized ultramicro-carbon fibre at $0.5 \mathrm{~V}$ vs. $\mathrm{Ag} / \mathrm{AgCl},{ }^{2}$ respectively. Both approaches suffer from severe potential interferences from the reduction of molecular oxygen and the oxidation of hydrogen peroxide and other significantly relevant analytes. It was also shown that peroxynitrous acid $\mathrm{ONOOH}$, the conjugated acid of $\mathrm{ONOO}^{-}$, can be reduced at a gold electrode in buffered acid solution, although it was not possible to estimate the electrode potential of the redox couple $\mathrm{ONOOH} / \mathrm{ONOOH}^{--}$strictly on the basis of the chemistry of $\mathrm{ONOOH} .{ }^{44}$ Thus, we have recently examined the reduction

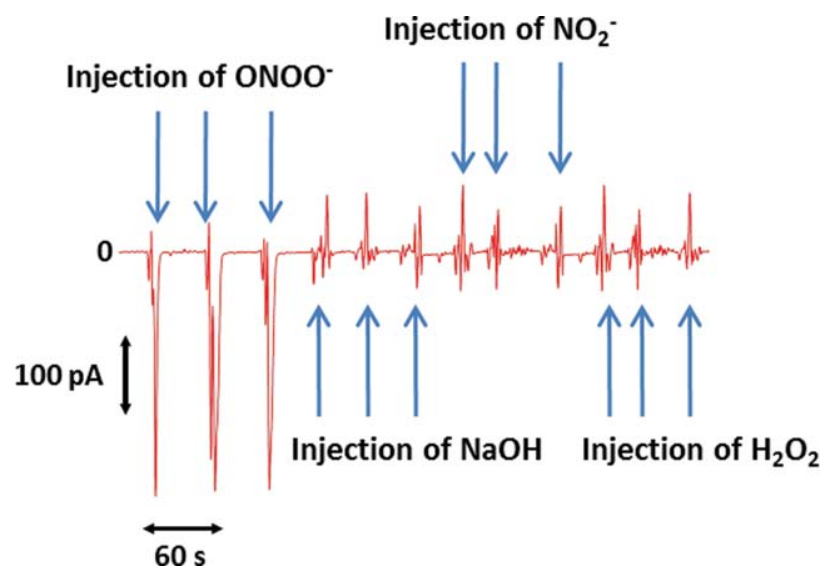

Fig. 7 Amperogram of 7 bare gold UMEs at $-0.1 \mathrm{~V} v s$. Ag/AgCl in PBS (pH 7.4) upon injection of $\mathrm{ONOO}^{-}(50 \mu \mathrm{M}), \mathrm{NaOH}(1700 \mu \mathrm{M}), \mathrm{NO}_{2}$ $(200 \mu \mathrm{M})$ and $\mathrm{H}_{2} \mathrm{O}_{2}(500 \mu \mathrm{M})$.

issue of $\mathrm{ONOOH}$ to assess the possibility of detecting the presence of $\mathrm{ONOO}^{-}$at bare gold electrode at neutral $\mathrm{pH}^{45} \mathrm{We}$ showed, by amperometry at rotating millimetric bare massive gold disc electrode, that the optimum potential that allows the reduction of $\mathrm{ONOOH}$ in neutral solution without interferences from hydrogen peroxide, dopamine, ascorbic acid and nitrite reduction and/or oxidation is $-0.1 \mathrm{~V}$ vs. $\mathrm{Ag} / \mathrm{AgCl}{ }^{45}$ In the following, this approach is applied to the designed ESA to detect the presence of $\mathrm{ONOO}^{-}$. The use of bare gold UMEs combined with the choice of the operating potential $-0.1 \mathrm{~V}$ avoids potential false-positives from the above mentioned interfering analytes in complex media and additional steps in the fabrication process.

Fig. 7 shows the typical amperograms obtained at $-0.1 \mathrm{~V}$ by 7 bare gold UMEs of the ESA upon the injection of aliquots of alkaline solutions of $\mathrm{ONOO}^{-}$, nitrite and hydrogen peroxide in PBS ( $\mathrm{pH}=7.4)$. Aliquots were manually injected in close proximity to the electrode surface with a micropipette. The injection was not followed by mixing because most of the $\mathrm{ONOO}^{-}$would have been decomposed by the end of the mixing. These data show the transient cathodic current obtained upon adding $\mathrm{ONOO}^{-}$ associated to the reduction of its protonated form. The shape of the amperogram is indicative of the fast degradation of the $\mathrm{ONOO}^{-}$that occurs within the first 15 seconds after its addition. $^{45}$

Further injections of sodium hydroxide, nitrite and hydrogen peroxide did not give rise to any current. Because $\mathrm{ONOO}^{-}$was injected manually, the exact distance between the sensing UMEs and the point of injection may vary, and so does the intensity of the recorded signal. Also, due to the very short lifetime of $\mathrm{ONOO}^{-}$, these results are only informative about changes of its flux or sustained production (bursts of $\mathrm{ONOO}^{-}$). Quantitative use of such analytical signals cannot accurately be developed as long as the kinetics of decomposition of $\mathrm{ONOO}^{-}$are not fully understood.

\section{Simultaneous sensing of NO and peroxynitrite}

In order to assess the possibility of sensing both $\mathrm{NO}$ and $\mathrm{ONOO}^{-}$ concurrently at the ESAs platform, two amperometric measurements were performed simultaneously at both networks 


\section{NO-sensors}

\section{Injection of DEA-NONOate + ONOO-}

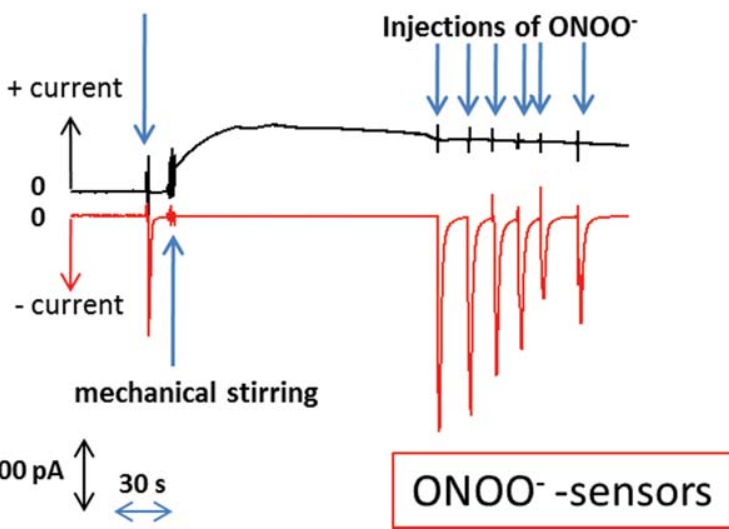

Fig. 8 Concurrent detection of $\mathrm{NO}$ and $\mathrm{ONOO}^{-}$by two simultaneous amperometric measurements upon injection of alkaline solution containing DEA-NONOate $(10 \mu \mathrm{M})+\mathrm{ONOO}^{-}(50 \mu \mathrm{M})$ and 5 minutes later injection of $\mathrm{ONOO}^{-}$alkaline solution $(50 \mu \mathrm{M})$. NO detection: at $+0.8 \mathrm{~V}$ vs. $\mathrm{Ag} / \mathrm{AgCl}$ at 7 gold UMEs coated by poly(eugenol)/poly(phenol). $\mathrm{ONOO}^{-}$detection at $-0.1 \mathrm{~V}$ vs. $\mathrm{Ag} / \mathrm{AgCl}$ at 7 bare gold UMEs.

of the ESA. To do so, a set of 7 UMEs was chemically modified by poly(eugenol) and poly(phenol) films and dedicated to the oxidation of $\mathrm{NO}$ at $0.8 \mathrm{~V}$, while another set of 7 bare gold UMEs was used uncoated and dedicated to the reduction of $\mathrm{ONOOH}$ at $-0.1 \mathrm{~V}$. After stabilisation of the background current for $c a .15$ minutes, an aliquot of alkaline solution containing both DEANONOate $(10 \mu \mathrm{M})$ and $\mathrm{ONOO}^{-}(50 \mu \mathrm{M})$ was rapidly injected. Due to the short lifetime of $\mathrm{ONOO}^{-}$, the injection of the alkaline solution must be performed close to the bare gold UMEs without immediate stirring. Thirty seconds later, the electrolytic solution was rapidly stirred in order to homogeneously spread the NO donor and detect its decomposition at the NO-sensors part of the ESA. Following this protocol, the presence of $\mathrm{ONOO}^{-}$was immediately detected upon the injection of the aliquot on the network of bare gold UMEs biased at $-0.1 \mathrm{~V}$, as seen at the lower part of Fig. 8. Thirty seconds later, and after stirring the electrolytic solution, production of $\mathrm{NO}$ is detected at the NO-sensor region of the ESA, as it can be seen in the upper part of Fig. 8.

Additional injections of $\mathrm{ONOO}^{-}$alkaline solution close to the bare gold UMEs biased at $-0.1 \mathrm{~V}$ (without stirring) allow observing again the cathodic amperometric signals related to the reduction of $\mathrm{ONOOH}$ without disturbing the detection of $\mathrm{NO}$ itself. These results clearly suggest that the two networks of 7 UMEs can be employed simultaneously for the detection of NO formed upon the decomposition of the $\mathrm{NO}$ donor, and $\mathrm{ONOO}^{-}$ without any crosstalk. As mentioned earlier, due to the fact that $\mathrm{ONOO}^{-}$was injected manually, the exact distance between the sensing UMEs and the point of injection may vary, and so does the intensity of the recorded signal.

\section{Conclusion}

In this work, we report on the design, microfabrication and analytical performances of a new fully integrated ESA, which for the first time allows simultaneous selective amperometric detection of $\mathrm{NO}$ and $\mathrm{ONOO}^{-}$. Several concepts were important for the design: (i) miniaturisation technologies permitted the creation of UMEs arrays on a glass surface that results in diffusion independent measurements, (ii) electrochemical surface modification enabled the creation of UMEs that were individually sensitive to either $\mathrm{NO}$ or $\mathrm{ONOO}^{-}$and (iii) integration of the chemical sensing array as well as the counter and reference electrodes onchip allows the system to be incorporated into a cell that can take measurements in biological medium. UMEs modified with a bilayer of poly(eugenol) and poly(phenol) were used for the electrochemical detection of $\mathrm{NO}$ at $0.8 \mathrm{~V} v s$. $\mathrm{Ag} / \mathrm{AgCl}$. The sensor showed a sensitivity of $0.56 \mathrm{nA} \mu \mathrm{M}^{-1}$ and was selective against major interfering analytes that are biologically relevant. Bare UMEs poised at $-0.1 \mathrm{~V} v s$. $\mathrm{Ag} / \mathrm{AgCl}$ were used for the selective detection of $\mathrm{ONOO}^{-}$. Finally, simultaneous detection of $\mathrm{NO}$ and $\mathrm{ONOO}^{-}$in PBS was successfully achieved to validate the proof of concept. Further applications of this device are now under evaluation for the assessment of $\mathrm{NO} / \mathrm{ONOO}^{-}$ratios produced by stimulated RAW 264.7 cell lines.

\section{Acknowledgements}

Financial support from the "Agence Nationale de la Recherche" (ANR France) in the framework of the project MECANO ANR08-PCVI-0018 is acknowledged. The authors are thankful to Fabien Josse for his scientific contributions, Laurent Pichon for the AFM measurements and Eva Cabet for SECM experiments.

\section{References}

1 (a) G. Krauss, Biochemistry of Signal Transduction and Regulation, Wiley VCH, Chichester, UK, 2008; (b) G. Thomas, Medicinal Chemistry: an Introduction, John Wiley and sons, Chichester, UK, 2nd edn, 2007.

2 C. Amatore, S. Arbault, M. Guille and F. Lemaitre, Chem. Rev., 2008, 108, 2585-2621, and references cited therein.

3 G. S. Wilson and M. A. Johnson, Chem. Rev., 2008, 108, 2462-2481.

4 D. L. Robinson, A. Hermans, A. T. Seipel and R. M. Wightman, Chem. Rev., 2008, 108, 2554-2584.

5 Methods in Nitric Oxide Research, ed. M. Feelisch and J. S. Stamler, Wiley, Chichester, UK, 1996.

6 E. Esposito and S. Cuzzocrea, Front. Biosci., 2009, 14, 263.

7 C. Szabo, H. Ischiropoulos and R. Radi, Nat. Rev. Drug Discovery, 2007, 6, 662-680.

8 M. Trujillo, M. Naviliat, M. N. Alvarez, G. Peluffo and R. Radi, Analusis, 2000, 28, 518-527.

9 P. Pacher, J. S. Beckman and L. Liaudet, Physiol. Rev., 2007, 87, 315424.

10 D. Jourd'heuil, F. L. Jourd'heuil, P. Kutchukian, R. A. Musah, D. Wink and M. B. Risham, J. Biol. Chem., 2001, 276, 28799-28805.

11 V. C. Besson, N. Croci, R. G. Boulu, M. Plotkine and C. MarchandVerrecchia, Brain Res., 2003, 989, 58-66.

12 F. Bedioui and N. Villeneuve, Electroanalysis, 2003, 15, 5-18.

13 M. Pontié and F. Bedioui, Analusis, 1999, 27, 564-570.

14 J. H. Zagal, S. Griveau, J. F. Silva, T. Nyokong and F. Bedioui, Coord. Chem. Rev., 2010, 257, 2755-2791.

15 F. Bedioui, D. Quinton, S. Griveau and T. Nyokong, Phys. Chem. Chem. Phys., 2010, 12, 9976-9989.

16 J. Oni, A. Pailleret, S. Isik, N. Diab, I. Radtke, A. Blochl, M. Jackson, F. Bedioui and W. Schuhmann, Anal. Bioanal. Chem., 2004, 378, 1594.

17 J. Castillo, S. Isik, A. Blöchl, N. Pereira-Rodrigues, F. Bedioui, E. Csöregi, W. Schuhmann and J. Oni, Biosens. Bioelectron., 2005, 20, $1559-1565$.

18 S.-C. Chang, N. Pereira Rodrigues, J. R. Henderson, A. Cole, F. Bedioui and C. McNeil, Biosens. Bioelectron., 2005, 21, 917-922. 
19 C. Wartelle, W. Schuhmann, A. Blöchl and F. Bedioui, Electrochim. Acta, 2005, 50, 4988.

20 N. Pereira Rodrigues, F. Bedioui, A. Deutsch, N. Zurgil, E. Afrimzon, Y. Shafran and M. Deutsch, Electrochem. Commun., 2006, 8, 341-347.

21 N. Pereira Rodrigues, N. Zurgil, S.-C. Chang, J. Henderson, F. Bedioui, C. Mcneil and M. Deutsch, Anal. Chem., 2005, 77, 2733

22 S.-C. Chang, N. Pereira Rodrigues, N. Zurgil, J. Henderson, F. Bedioui, C. Mcneil and M. Deutsch, Biochem. Biophys. Res. Commun., 2005, 327, 979 .

23 C. Amatore, S. Arbault, Y. Chen, C. Crozatier and I. Tapsoba, Lab Chip, 2007, 7, 233-238.

24 M. K. Hulvey and R. S. Martin, Anal. Bioanal. Chem., 2009, 393, 599605.

25 B. A. Patel, M. Arundell, R. G. W. Quek, S. L. R. Harvey, I. R. Ellis, M. M. Florence, A. E. G. Cass, A. M. Schor and D. O'Hare, Anal. Bioanal. Chem., 2008, 390, 1379-1387.

26 R. Trouillon, C. Cheung, B. A. Patel and D. O'Hare, Biochim. Biophys. Acta, Gen. Subj., 2010, 1800, 929-936.

27 M. N. Hughes and G. Nicklin, J. Chem. Soc. A, 1968, 2, 450-452.

28 K. M. Robinson and J. S. Beckman, Methods Enzymol., 2005, 396, 207-214.

29 D. S. Bohle, B. Hansert, S. C. Paulson and B. D. Smith, J. Am. Chem Soc., 1994, 116, 7423-7424

30 C. Beriet, R. Ferrigno and H. H. Girault, J. Electroanal. Chem., 2000, 486, 56-64.

31 J. Guo and E. Lindner, Anal. Chem., 2009, 81, 130-138.
32 S. M. Lee, J. J. Licari and I. Litant, Metall. Mater. Trans. B, 1970, 1, 701-711.

33 G. M. Zarkadas, A. Stergiou and G. Papanastasiou, Electrochim. Acta, 2005, 50, 5022-5031.

34 Scanning Electrochemical Microscopy, ed. A. J. Bard and M. V. Mirkin, Marcel Dekker, New York, USA, 2001.

35 S. Fletcher and M. D. Horne, Electrochem. Commun., 1999, 1, 502-512.

36 O. Ordeig, J. Del Campo, F. X. Muñoz, C. E. Banks and R. G. Compton, Electroanalysis, 2007, 19, 1973-1986.

37 A. Ciszewski and G. Milczarek, Talanta, 2003, 61, 11-26, and references cited therein.

38 B. J. Privett, J. H. Shin and M. H. Schoenfisch, Chem. Soc. Rev., 2010, 39, 1925-1935, and references cited therein.

39 D. Quinton, A. G. Porras-Gutierrez, S. Gutierrez-Granados, S. Griveau and F. Bedioui, ECS Trans., 2010, 25, 39-46.

40 S. Griveau, C. Dumézy, P. Goldner and F. Bedioui, Electrochem. Commun., 2007, 9, 2551-2556, and references cited therein.

41 J. Xue, X. Ying, J. Chen, Y. Xian, L. Jin and J. Jin, Anal. Chem., 2000, 72, 5313-5321

42 R. Kubant, C. Malinski, A. Burewicz and T. Malinski, Electroanalysis, 2006, 18, 410-416.

43 J. Sandoval Cortes, S. Gutierrez Granados, A. Alatorre, J. A. Lopez Jiminez, S. Griveau and F. Bedioui, Electroanalysis, 2007, 19, 61-64.

44 C. Kurz, X. Zeng, S. Hannemann, R. Kissner and W. H. Koppenol, J. Phys. Chem. A, 2005, 109, 965-969.

45 D. Quinton, S. Griveau and F. Bedioui, Electrochem. Commun., 2010, 12, 1446-1449. 